\title{
Deep seafloor arrivals in long range ocean acoustic propagation
}

\author{
Ralph A. Stephen ${ }^{\text {a) }}$ and S. Thompson Bolmer \\ Geology and Geophysics Department, Woods Hole Oceanographic Institution, 360 Woods Hole Road, \\ Woods Hole, Massachusetts, 02543
}

Ilya A. Udovydchenkov
Applied Ocean Physics and Engineering Department, Woods Hole Oceanographic Institution,
360 Woods Hole Road, Woods Hole, Massachusetts, 02543

Peter F. Worcester and Matthew A. Dzieciuch

Scripps Institution of Oceanography, University of California, San Diego 9500 Gilman Drive, La Jolla, California, 92093

Rex K. Andrew and James A. Mercer

Applied Physics Laboratory, University of Washington, 1013 Northeast 40th Street, Seattle, Washington, 98105-6698

John A. Colosi

Department of Oceanography. Naval Postgraduate School, 833 Dyer Road, Monterey, California, 93943

\begin{abstract}
Bruce M. Howe
Department of Ocean and Resources Engineering, University of Hawai' i at Manoa, 2540 Dole Street, Honolulu, Hawaii, 96822
\end{abstract}

(Received 11 December 2012; revised 30 May 2013; accepted 14 June 2013)

\begin{abstract}
Ocean bottom seismometer observations at $5000 \mathrm{~m}$ depth during the long-range ocean acoustic propagation experiment in the North Pacific in 2004 show robust, coherent, late arrivals that are not readily explained by ocean acoustic propagation models. These "deep seafloor" arrivals are the largest amplitude arrivals on the vertical particle velocity channel for ranges from 500 to $3200 \mathrm{~km}$. The travel times for six (of 16 observed) deep seafloor arrivals correspond to the sea surface reflection of an out-of-plane diffraction from a seamount that protrudes to about $4100 \mathrm{~m}$ depth and is about $18 \mathrm{~km}$ from the receivers. This out-of-plane bottom-diffracted surface-reflected energy is observed on the deep vertical line array about $35 \mathrm{~dB}$ below the peak amplitude arrivals and was previously misinterpreted as in-plane bottom-reflected surface-reflected energy. The structure of these arrivals from 500 to $3200 \mathrm{~km}$ range is remarkably robust. The bottom-diffracted surface-reflected mechanism provides a means for acoustic signals and noise from distant sources to appear with significant strength on the deep seafloor. (C) 2013 Acoustical Society of America.
\end{abstract}

[http://dx.doi.org/10.1121/1.4818845]

PACS number(s): 43.30.Gv, 43.30.Re, 43.30.Nb, 43.30.Ma [JIA]

Pages: $3307-3317$

\section{INTRODUCTION}

The goal of bottom interacting ocean acoustics is to observe and explain sound and vibration near and on the seafloor. Stephen et al. (2009) showed that the sound/vibration field in the $50-100 \mathrm{~Hz}$ band from distant sources (500-3200 km range) in the deep $(\sim 5,000 \mathrm{~m})$ ocean is much more complex at the seafloor than $750 \mathrm{~m}$ above the seafloor. In this paper we show, for the first time, that the significant arrivals on the deep seafloor, which are relatively weak arrivals in the upper ocean, become dominant due to a combination of the decay of the traditional ocean-borne paths and of the substantially quieter ambient noise in the deep ocean. For a subset of the "deep seafloor arrivals," the dominant propagation path to the deep ocean, in our experiment, corresponds to energy that traveled primarily through the ocean sound channel, diffracted from an out-of-sagittal-

\footnotetext{
a) Author to whom correspondence should be addressed. Electronic mail: rstephen@whoi.edu
}

plane seamount near the receivers (Seamount B in Fig. 1) and reflected from the free surface back down to the receivers on the seafloor. (The sagittal plane is the vertical plane between the source and receiver.) These "bottomdiffracted surface-reflected arrivals" are significantly larger, at some ranges by as much as $20 \mathrm{~dB}$, than the arrivals that traveled through the ocean sound channel directly to the seafloor. At $3200 \mathrm{~km}$ range, the direct ocean sound channel paths are not observed at all on the deep seafloor and the only observed arrivals are the bottom-diffracted surfacereflected paths.

In this paper, we present observations of deep seafloor arrivals on all three (west, south, and east) ocean bottom seismometers (OBS), not just the south OBS as in the 2009 paper. We show that a subset of six of the deep seafloor arrivals are observed on all three OBSs, near $5000 \mathrm{~m}$ depth, and are a delayed replica, by about $2 \mathrm{~s}$, of the arrival pattern predicted by the parabolic equation (PE) method at the deepest element of the deep vertical line array (DVLA) at $4250 \mathrm{~m}$ depth. Triangulation of these delay times indicates that these 

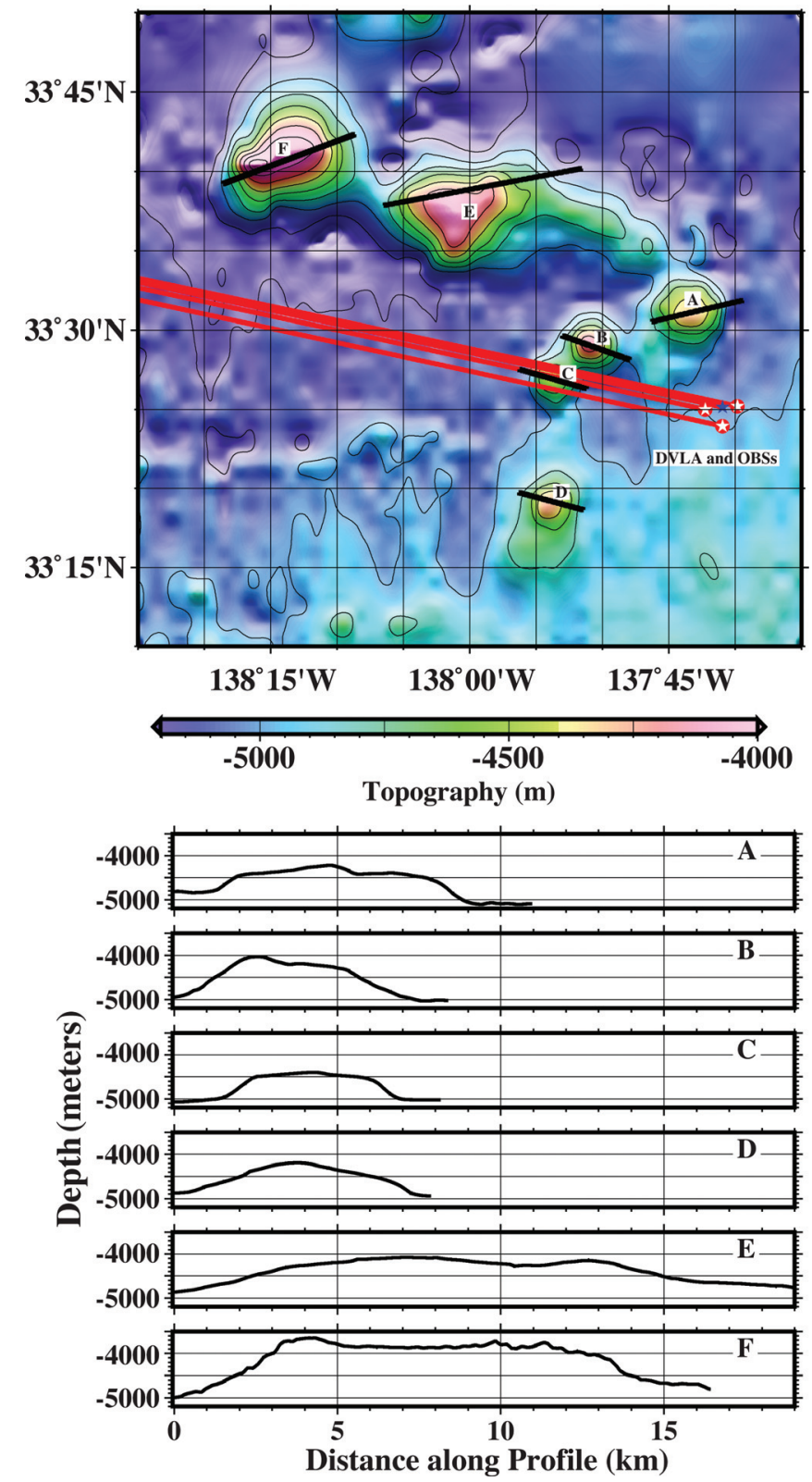

FIG. 1. During the long-range ocean acoustic propagation experiment (LOAPEX), transmissions were made from 50 to $3200 \mathrm{~km}$ range from the deep vertical line array (DVLA, blue star). Three ocean bottom seismometers (OBSs - white stars in red circles) were deployed east, west and south and about $2 \mathrm{~km}$ from the DVLA. All of the geodesic paths to these receivers (red lines) are within about $3 \mathrm{~km}$ of one another. The satellite derived bathymetry (Smith and Sandwell, 1997) shows six prominent seafloor features, small seamounts (labeled A-F). Profiles across the six seamounts, indicated by black lines on the bathymetry map, are compared in the bottom six panels.

deep seafloor arrivals are incident from a seamount that rises to about $4100 \mathrm{~m}$, is about $18 \mathrm{~km}$ from the receivers, and is offset laterally more than $2 \mathrm{~km}$ from the source-receiver geodesic. Further, the delay times are consistent with arrival times predicted by ray tracing for bottom-diffracted surfacereflected energy from the out-of-plane seamount.

The observation of these deep seafloor arrivals suggests that deep seafloor ambient noise and signal-to-noise ratios (SNR) will be a function of local topography around the receivers. Deep seafloor arrivals provide a means for acoustic signals and noise from distant sources to penetrate into shadow zones (created by simple focusing in the sound channel or due to bathymetric blockage) on the deep seafloor. It is conceivable that the late arrival pattern for distant sources would be a function of azimuth and that the "bathymetric finger print" could be a useful tool in determining the azimuth to distant sources from just a few seafloor sensors. Given the ubiquity of seamounts, the existence of these new paths will impact ambient noise models by providing paths for noise from distant storms, whales, and shipping (Gaul et al., 2007) to reach the deep seafloor, well below the surface conjugate depth.

\section{BACKGROUND}

The data discussed in this paper and in Stephen et al. (2009) were acquired on the Long-Range Ocean Acoustic Propagation Experiment (LOAPEX) that was carried out in the northeast Pacific Ocean between 10 September and 10 October 2004 (Mercer et al., 2009). The goal of LOAPEX was to improve our understanding of a number of issues in long-range, deep-water acoustic propagation including the effects of bottom interaction on near-bottom receivers. Four OBSs were deployed about $2 \mathrm{~km}$ from a DVLA (one OBS did not return useful data) and the source transmitted at nominal ranges of 50, 250, 500, 1000, 1600, 2300, and $3200 \mathrm{~km}$ along a geodesic where the water depth exceeded $4400 \mathrm{~m}$ everywhere. The acoustic source was suspended at depths of 350,500 , or $800 \mathrm{~m}$ and transmitted primarily phase-coded M-sequences (short for "binary maximal-length sequences") with a bandwidth from about 50 to $100 \mathrm{~Hz}$. [A useful summary of the transmission strategy used in long-range ocean acoustic and tomography experiments is given by Munk et al. (1995).] For the data presented in this paper, the Msequence carrier frequency was $68.2 \mathrm{~Hz}$ (called M68.2) and the source depth was $350 \mathrm{~m}$. The duration of the M68.2 sequences was $30 \mathrm{~s}$, and sequential transmissions were repeated for periods of 20-80 min. Enhanced signal-to-noise ratios and improved resolution (27 $\mathrm{ms}$ in time, $40 \mathrm{~m}$ in range) were achieved by matched filtering (also called pulse compression or replica correlation) (Baggeroer and Kuperman, 1983; Birdsall, 1976; Birdsall and Metzger, 1986; Birdsall et al., 1994; Golomb, 1982; Metzger, 1983). Sequences were not stacked prior to replica correlation, but SNR was further improved by incoherently stacking the magnitude of the replica-correlated traces. Further details of the processing and results at other source depths, ranges, and carrier frequencies are presented in Stephen et al. (Stephen et al., 2008; Stephen et al., 2012).

The fundamentals of long range sound propagation in the deep ocean have been presented by Ewing and Worzel (1948), Clay and Medwin (1977), and Jensen et al. (1994). Stephen et al. (2009) reported a new class of arrivals in long range ocean acoustic propagation that were observed in the replica correlated signals acquired on the south OBS deployed during LOAPEX. They compared the vertical geophone data from the south OBS at $4973 \mathrm{~m}$ depth, beneath the DVLA, with data from the deepest hydrophone on the DVLA at $4250 \mathrm{~m}$ depth (DVLA-4250). The results of the preliminary analysis showed: (1) That the south OBS had more arrivals than DVLA-4250, (2) that the first arrivals on 
the south OBS and DVLA-4250 corresponded to energy in the first deep arriving path predicted by the Parabolic Equation (PE) solution, (3) that the later arrivals on the south OBS, which were much larger in amplitude, were not explained by the Parabolic Equation solution, and (4) that it was the later, unexplained arrivals, called "deep seafloor" arrivals, that contributed to the seafloor receptions at $3200 \mathrm{~km}$ range.

In summary, the 2009 paper described three types of arrivals that were observed on deep seafloor sensors: (1) "PE predicted arrivals" are observed arrivals the travel time of which can be predicted by PE propagation models. (2) "Deep shadow zone arrivals" are not predicted by PE propagation models, but they occur at the same time as shallower cusps in the time fronts (caustics) (Dushaw et al., 1999). They have been attributed to diffraction and scattering by internal waves (leakage) below the caustics (Van Uffelen et al., 2009). The magnitude of deep shadow zone arrivals decreases with subsequent cusps in the time fronts, as expected for decay below progressively shallower turning point depths. (3) "Deep seafloor arrivals" were first discussed in Stephen et al. (2009). Their arrival times are not predicted by PE models, and they do not coincide with PE predicted turning points (except coincidentally). In fact they have even been observed to occur after the finale of the time front. In the LOAPEX experiment, they are the largest arrivals on the seafloor at ranges from 500 to $3200 \mathrm{~km}$. This classification of three types of arrivals will be continued in this paper.

\section{THE OBSERVED ARRIVALS}

Record sections, a display of the stacked traces of the time-series as a function of range $(250-3200 \mathrm{~km})$ and reduced time, are a convenient way to display and compare arrival patterns (Fig. 2). "Stacked" traces are the simple sum of all good time-compressed traces acquired (Table I). Reduced time is the time from the start of the transmission minus the range divided by $1.485 \mathrm{~km} / \mathrm{s}$. In reduced time, all of the arrivals of interest span about $10 \mathrm{~s}$; in unreduced time, they would span $\sim 2000$ s! (Note that Fig. 2 shows "receiver gathers" where all of the traces for a given receiver are plotted together. Later, in Fig. 4, we will show "source gathers" where all of the traces for a given source are plotted together.)

Details of ranges and timing including clock drifts, since all four of the receivers in Fig. 2 were recording on their own autonomous clocks, are given in Stephen et al. (Stephen et al., 2008; Stephen et al., 2012). The ranges have not changed since the 2008 technical report and are the same as in Stephen et al. (2009). No corrections have been applied for mooring motion or source motion.

Timing corrections were done in two stages, coarse prior to September 2009 [including Stephen et al. (2009)] and Figs. 2, 3(d) and 3(e) and fine afterward (Fig. 4 and the triangulation analysis). The distinction is based on how carefully the first breaks of the arrival times were picked. In both stages, time shifts were applied to get the first observed PEpredicted arrival to align with the modeled arrival (essentially using the PE model time as "zero-time"). In the coarse stage, for the 2008 technical report and 2009 paper, using traces plotted at $1 \mathrm{~s} / \mathrm{cm}$, time corrections were applied of about $0.05-0.2 \mathrm{~s}$ and the accuracy, after the corrections, was estimated as $0.2 \mathrm{~s}$. After the fine stage, corrections were applied, using traces plotted at $0.1 \mathrm{~s} / \mathrm{cm}$, the estimated accuracy was $0.02 \mathrm{~s}$ when SNR was good (for example, the

\section{a) West OBS Geo, $4997 \mathrm{~m}$}

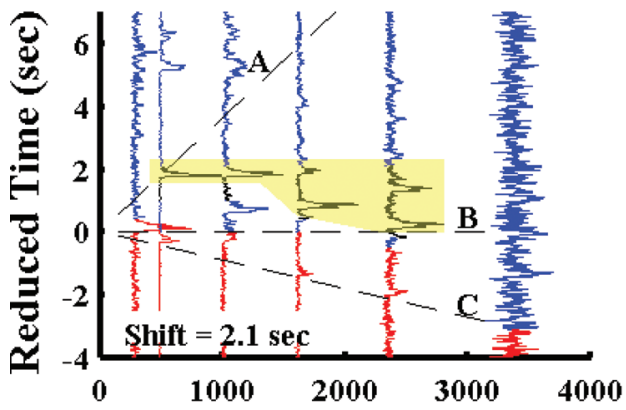

c) South OBS Geo, $4973 \mathrm{~m}$

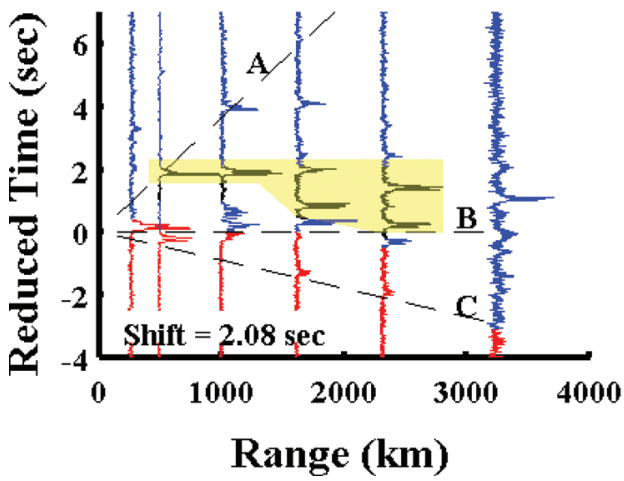

b) DVLA Hyd, $4250 \mathrm{~m}$

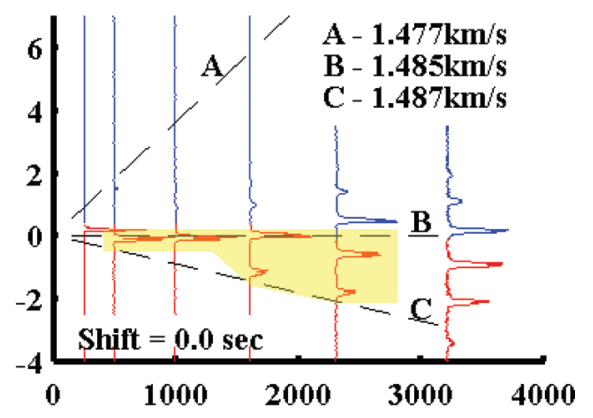

d) East OBS Geo, $5035 \mathrm{~m}$

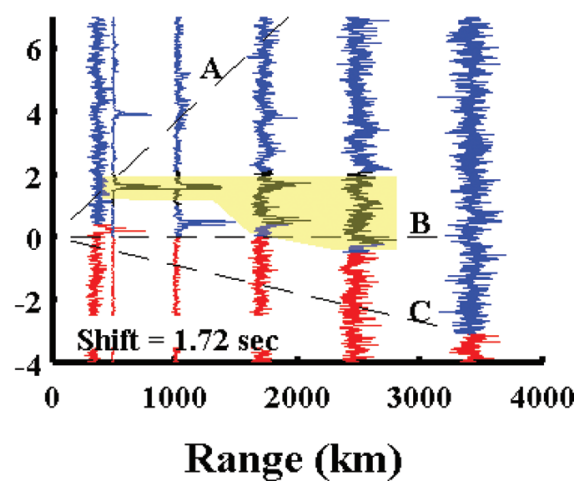

FIG. 2. Stacks of the replica-correlated traces are displayed as a function of range for DVLA-4250 and all three of the OBSs that returned data. The nominal ranges are 250, 500, 1000, 1600, 2300 , and $3200 \mathrm{~km}$. Reduced time is the actual travel time from the source minus the range divided by $1.485 \mathrm{~km} / \mathrm{s}$. The red section of each trace indicates the PE predicted arrivals, and the blue trace indicates deep shadow-zone and deep seafloor arrivals as discussed in Stephen et al. (2009). The yellow region is the same shape on all four figures but has been shifted in time as indicated. Dashed lines correspond to three relevant speeds: A, $1.477 \mathrm{~km} / \mathrm{s}-$ the apparent sound speed of the latest arrival at 500, 1000, and $1600 \mathrm{~km}$ range; $\mathrm{B}, \quad 1.485 \mathrm{~km} / \mathrm{s}$ - the apparent sound speed of the largest PE predicted arrival on DVLA-4250, which seems to separate the known early arrivals from the late unknown arrivals; and C, $1.487 \mathrm{~km} / \mathrm{s}$ - the apparent sound speed of the earliest arriving energy at the OBSs and DVLA-4250. 
TABLE I. Approximate elapsed times and the number of acceptable sequences (NN_South, NN_East, NN_West, and NN_DVLA at the south, east, and west OBSs and DVLA-4250, respectively) used for the stacked traces in Figs. 2-4.

\begin{tabular}{|c|c|c|c|c|c|}
\hline Nominal Range (km) & Elapsed time (h) & NN_South & NN_East & NN_West & NN_DVLA \\
\hline 250 & 9 & 421 & 430 & 426 & 27 \\
\hline 500 & 15 & 690 & 690 & 683 & 480 \\
\hline 1000 & 34 & 1345 & 1408 & 1340 & 1080 \\
\hline 1600 & 28 & 975 & 1098 & 970 & 930 \\
\hline 2300 & 14 & 606 & 613 & 616 & 576 \\
\hline 3200 & 15 & 599 & 615 & 568 & 576 \\
\hline
\end{tabular}

DVLA at $500 \mathrm{~km}$ range) and about $0.05 \mathrm{~s}$ when SNR was poor (for example, the west OBS at 1000-2300 km range). For the east OBS at $500 \mathrm{~km}$ range, no PE predicted arrival was observed. In this case, we applied the timing correction for the $250 \mathrm{~km}$ transmissions. Because we set the clock corrections to agree with the PE modeled arrivals, any discrepancy between the actual ranges and the ranges used in the PE modeling were included in the timing correction.

The pattern of arrivals at the OBSs at $5000 \mathrm{~m}$ depth is quite different from the pattern of arrivals at DVLA-4250. In Fig. 2, compare the number of arrivals in the OBS panels [Figs. 2(a)-2(d)] with the number of arrivals in the DVLA4250 panel [Fig. 2(b)]. Most of the major events on DVLA4250 [Fig. 2(b)] are predicted by the PE model (indicated in red) but some correspond to deep shadow zone arrivals [indicated in blue in Fig. 2(b)] (Van Uffelen et al., 2009), as demonstrated in Figs. 4 and 5 of Stephen et al. (2009). The six deep seafloor arrivals highlighted in yellow on the OBSs [Figs. 2(a), 2(c) and 2(d)], from 500 to $2300 \mathrm{~km}$, form a consistent pattern and appear to be a delayed replica of the PE predicted arrival pattern on DVLA-4250 [highlighted in yellow in Fig. 2(b)]. The deep seafloor arrivals are the largest amplitude arrivals on the OBS traces. Because these arrivals are delayed a fixed amount regardless of range, the delay is introduced near the receivers.

There are also late arrivals on the DVLA but they are much weaker. Data time fronts and traces on the DVLA for $500 \mathrm{~km}$ range are compared with PE model time fronts and traces in Fig. 3.

The third arrival, indicated by the arrow in Fig. 3(e), is the second largest event on the DVLA-4250 data trace but is still weak, about $35 \mathrm{~dB}$ down from the peak amplitude on the DVLA and is barely detectable in Fig. 2(b). It clearly corresponds to waterborne energy and has the characteristics of bottom-reflected surface-reflected energy. Similar arrivals were not observed on the DVLA at longer ranges. It will be shown below that the "arrow event" on DVLA-4250 [Fig. $3(\mathrm{e})$ ] and the highlighted deep seafloor arrivals [in yellow in Figs. 2(a), 2(c) and 2(d)] propagated as PE predicted energy to Seamount B and diffracted from Seamount B to the sea surface and back down to the receivers (bottom-diffracted surface-reflected).

The highlighted deep seafloor arrivals on the OBSs are a very precisely delayed replica of the PE predicted arrivals on DVLA-4250. This is shown in Fig. 4 where the traces have been grouped with respect to common sources and the time scale has been expanded to focus on the deep seafloor arrivals highlighted in yellow in Fig. 2 [Figs. 2(a), 2(c) and 2(d), blue traces]. The DVLA-4250 trace (cyan) has been delayed $2.08 \mathrm{~s}$, and there is excellent agreement in waveform and arrival time with the south OBS trace, for all nominal ranges. Although the east OBS has poor SNR at the longer ranges, the delayed $\mathrm{PE}$ predicted arrival pattern across the four ranges on DVLA-4250 appears essentially identically on the three OBSs at $5000 \mathrm{~m}$ depth. Arrival times are picked for six events on the south OBS as indicated by the solid black lines. The dashed black lines on the west and east traces, which align well with the arrivals, are offset by 0.015 and $0.365 \mathrm{~s}$, respectively, from the south picks at all ranges. All six arrivals, across four ranges from 500 to $2300 \mathrm{~km}$ range, occur on the three OBSs and DVLA-4250 at times given by the picked arrival times for the south OBS and the three delays given in this paragraph. These delays and the delay of $1.678 \mathrm{~s}$ between the PE predicted and bottomdiffracted surface-reflected arrival on DVLA-4250 (Fig. 3) are used in the following text to triangulate to the point where conversion from the PE predicted path to the bottomdiffracted surface-reflected path occurs.

This observation is remarkable for two reasons. First the deep seafloor arrivals on the OBSs occur more than $2 \mathrm{~s}$ after the PE predicted arrival times. Second it is strange that the PE predicted arrival pattern for $4250 \mathrm{~m}$ depth should appear at $5000 \mathrm{~m}$ depth. [For a comparison of the PE predicted arrival patterns at the two depths, see Fig. 5 of Stephen et al. (2009).] The pattern occurs because the sound from long ranges is hitting the top of a seamount, which is coincidentally also near $4250 \mathrm{~m}$. The $\sim 2 \mathrm{~s}$ delay occurs because the sound is scattered from the top of the seamount to the sea surface and back down to the seafloor.

\section{TRIANGULATION FOR THE CONVERSION POINT}

We assume that the arrival times of the PE predicted events are known from PE modeling. (In fact we used the PE predicted events to synchronize the clocks.) Because the deep seafloor arrival pattern on the OBSs is steady at $500 \mathrm{~km}$ range and beyond, we model just the $500 \mathrm{~km}$ range.

We use the group speed (range divided by arrival time) of the first PE predicted arrival at DVLA-4250 $(1.4869 \mathrm{~km} / \mathrm{s}$ for $500 \mathrm{~km}$ range) and the range from the transmission station to the conversion point to compute the time spent on the PE-predicted path to the conversion point (Fig. 5, black line). This time is the same for all four receivers. Then we plot the "residual time" for the deep seafloor and bottom- 

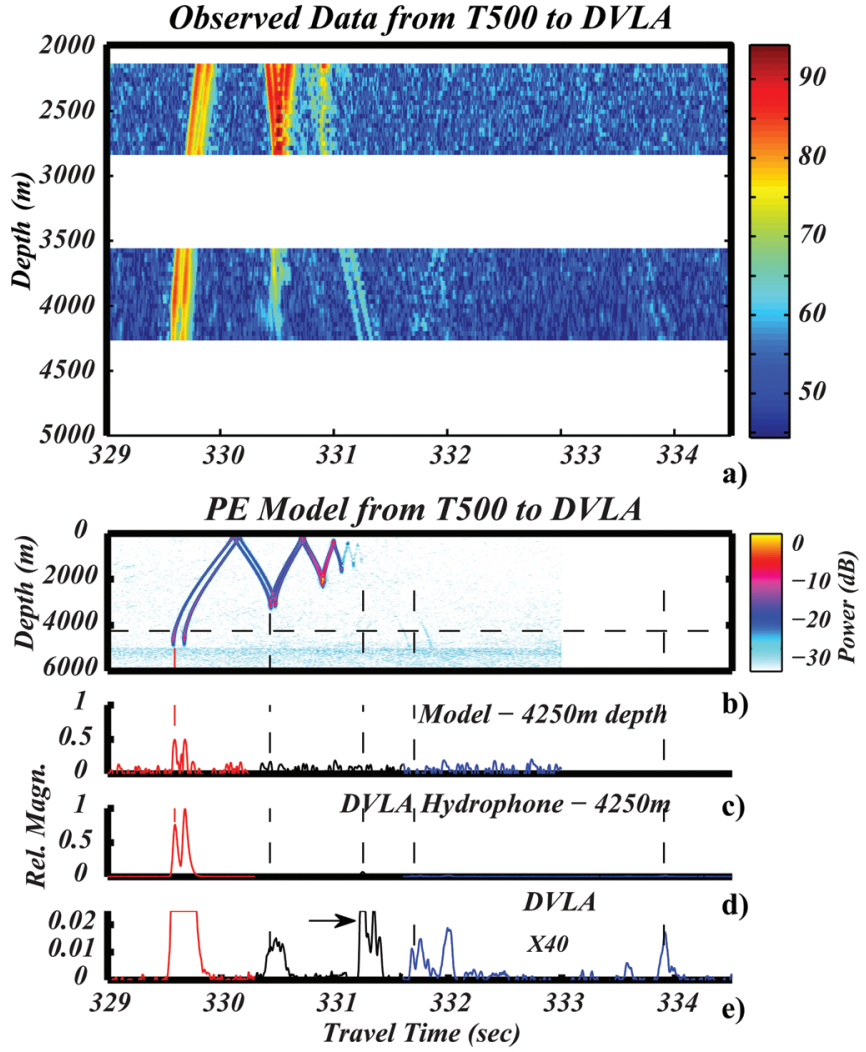

FIG. 3. (a) Time front display of the stack of ten transmissions (over $5 \mathrm{~min}$ ) corrected for array motion, for the 40 available hydrophone elements on the DVLA for the source at $500 \mathrm{~km}$ range and a depth of $350 \mathrm{~m}$ (sequence M68.2). The color bar, in units of $\mathrm{dB}$ re: $1 \mu \mathrm{Pas}$, is normalized to the peak amplitude on the plot and has a dynamic range of $50 \mathrm{~dB}$. (b) The PE model time front. (c) The model time trace at $4250 \mathrm{~m}$ depth. (d) The observed data at $4250 \mathrm{~m}$ depth). (e) The observed data with a gain of 40 where the larger amplitude arrivals are clipped in the display. Five arrivals can be observed at $4250 \mathrm{~m}$ depth, from left to right: (i) $\sim 329.6 \mathrm{~s}$ - the prominent PE predicted arrival; (ii) $\sim 330.4 \mathrm{~s}$ - a weak arrival corresponding to a deep shadow zone arrival below the first turning point; (iii) $\sim 331.25 \mathrm{~s}$-bottom-diffracted surface-reflected energy diffracted from Seamount B (see text); (iv) $\sim 331.7 \mathrm{~s}$ - very weak arrival corresponding to the seafloor reflection of the bottom-diffracted surface-reflected arrival; and (v) $\sim 333.9 \mathrm{~s}$ - an extremely weak indication of energy on the lower half of the deep section of the DVLA, that appears to be a water multiple of the bottom-diffracted surfacereflected arrival. The bottom-diffracted surface-reflected event (arrow) occurs $1.678 \mathrm{~s}$ after the PE predicted arrival.

diffracted surface-reflected arrivals at each receiver versus the "residual range" from the scattering point to each receiver (yellow lines). The residual arrival times in the observed data are adjusted to a common depth (here we use $4997 \mathrm{~m}$, the depth of the west OBS, as the datum) by computing the time difference between the ray-traced arrival time curves (Figs. 6 and 7) for the two depths (actual and datum) at the appropriate range, and applying the difference to the observed arrival time. Examples of data and model travel-time curves are shown in Fig. 8 for two test points on Seamount B. The model travel-time curves assume that the scatterer depth is $4250 \mathrm{~m}$ for all test points. Moving the scatterer depth from 4200 to $4450 \mathrm{~m}$ changes the ray traced arrival times by less than $0.1 \mathrm{~s}$.

To determine the best conversion point location we consider three error criteria. First, the residual arrival time versus residual range points (on the travel-time plots) should have the same horizontal propagation speed from the conversion point, that is, they should fall on a straight line. (Note that the ray traced arrival times in Fig. 8 all fall precisely on a straight line.) A measure of how well the travel times fit a straight line is given by the least-square error ("LSQ error") of the linear regression. Second, the travel times of the residuals should be predicted by ray tracing for a surface reflected arrival, accounting for the various depths of the receivers. This raytrace prediction error is the root-mean-square of the offsets ("RMS offset") between the predicted and observed travel times at the four ranges. Third, the horizontal phase speed, the inverse of the slope of the travel-time line, should also be predicted by ray tracing. The horizontal phase speed agreement is given as a percentage of the difference between the predicted and observed values ("phase speed difference"). Examples of the error criteria are shown in Fig. 8.

We looked for the minima in the three error surfaces on two spatial grids. We first considered a coarse grid at $1 \mathrm{~min}$ intervals over the region spanning all six seamounts (Fig. 9). The three error surfaces (the least square error of the linear regression, the RMS offset between observed and predicted arrival times, and the difference between observed and modeled phase speeds) over this region all have lower values at Seamount B compared to the other seamounts.

To refine the conversion point further, we computed the error surfaces on a finer grid ( $0.1 \mathrm{~min}$ intervals) over Seamount B (the box in Fig. 5). Selected contours from the three error surfaces are overlain on the Seamount B isobaths in Fig. 10. Combining the estimated time resolution of the M-sequence $(0.027 \mathrm{~s})$ with the estimated discrepancies between the various clocks $(0.020 \mathrm{~s})$ gives an estimate of the experimental timing error of $\sim 0.05 \mathrm{~s}$. This value was used for the LSQ Error contour. Twice this value, to allow for errors such as source depth in the modeling procedure, was used for the RMS offset contour. All three error criteria overlay segments of Seamount B with a depth between 4200 and $4300 \mathrm{~m}$. No single point on Seamount B meets all three constraints. The LSQ error and phase speed error regions overlap near test point 1 . The LSQ error and RMS offset criteria give a different location indicated by test point 2 .

The residual travel-time curves for test points 1 and 2 are compared in Fig. 8. At both test points, the arrival time of the bottom-diffracted surface-reflected arrival on DVLA-4250 falls on the same straight line as the deep seafloor arrivals on the OBSs. Both test points give LSQ errors less than $0.05 \mathrm{~s}$. This confirms that all four arrivals are consistent with the assumed model: PE predicted propagation from the sources to the seamount and bottom-diffracted surface-reflected propagation from the seamount to the receivers. Test point 1 has good phase speed (inverse slope) agreement with ray theory (less than $2 \%$ error) but predicts the overall arrival time relatively poorly $(0.35 \mathrm{~s}$ error). Test point 2 gives a much better prediction of the overall arrival time $(0.09 \mathrm{~s}$ error) but does not estimate the phase speed as well (6.2\% error).

\section{SIGNAL LEVELS, NOISE LEVELS, AND SIGNAL TO NOISE RATIOS}

All of the traces plotted in the figures in the preceding text are normalized to the maximum amplitude. What are the 
a) $\mathbf{T 5 0 0}$
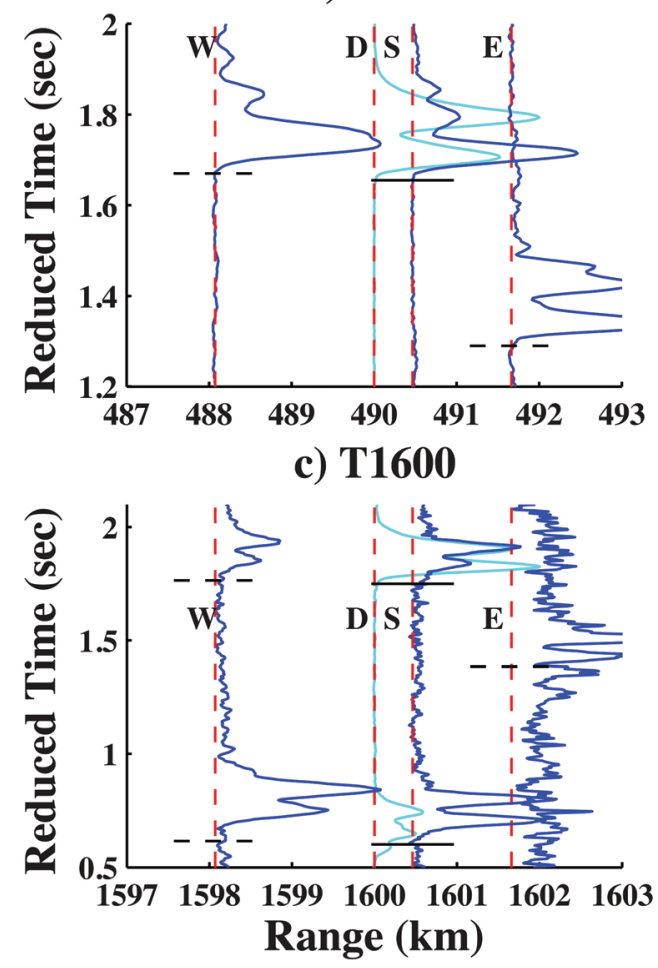

b) $\mathbf{T 1 0 0 0}$
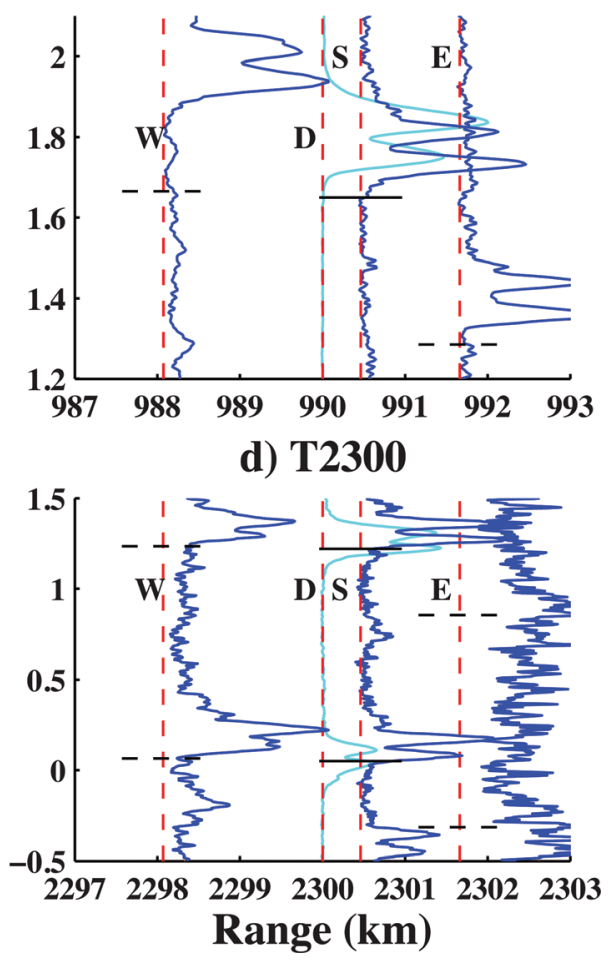

FIG. 4. Stacked traces are grouped with respect to source (T500, T1000, $\mathrm{T} 1600$, and T2300 corresponding to the nominal ranges of the source from the DVLA) and expanded to focus on the deep seafloor arrivals highlighted in yellow in Fig. 2 (blue; W, west OBS; $\mathrm{S}$, south OBS; E, east OBS). The DVLA-4250 trace (cyan, D) is delayed by $2.08 \mathrm{~s}$ at all ranges. Solid black horizontal lines indicate the picked arrival times on the south OBS. The dashed black lines on the west and east traces are simply offset by 0.015 and $-0.365 \mathrm{~s}$, respectively, from the south picks (solid black lines) at all ranges. The dashed red lines are plotted at the actual receiver ranges and indicate the zero level of the time-compressed traces. absolute levels of signals and noise on the OBSs and DVLA4250? DVLA-4250 is a hydrophone measuring acoustic pressure in micropascals. All of the OBS data shown in the preceding text, however, are from geophones measuring the particle velocity in meter/second. So to do a quantitative comparison of SNRs, one needs a conversion factor from vertical particle velocity to pressure at the seafloor. This can be done either from the acoustic impedance relation or by actually measuring ratios from the data.

Assume that acoustic pressure and particle velocity are simply related by the impedance (pressure is impedance times particle velocity) as for a plane wave in an infinite homogeneous fluid medium. This assumption implies that the signals and noise are coming directly from above because we are considering only the vertical particle velocity. Acoustic impedance is density times wave speed which, assuming $1000 \mathrm{~kg} / \mathrm{m}^{3}$ and $1500 \mathrm{~m} / \mathrm{s}$, respectively, gives $243.5 \mathrm{~dB}$ re: $1 \mu \mathrm{Pa} /(\mathrm{m} / \mathrm{s})$.

Alternatively the pressure to particle velocity ratio can be estimated directly from the LOAPEX OBS data. The OBSs had both hydrophones and geophones, but both were system noise limited (Fig. 11). The hydrophones were so badly system noise limited that even the pulse compression gain was insufficient to render observable arrivals. There were intervals, however, when the ambient noise levels rose above the system noise on both sensors. All of the data from the south OBS during the LOAPEX experiment (September 15 to October 10,2004 ) were scanned to locate these intervals and RMS levels were computed for the $60-80 \mathrm{~Hz}$ band. [Spectra of the M-sequences are given in Mercer et al. (2005)]. There were 1247 65.5-s intervals that yielded a pressure to particle velocity ratio of $251.2 \pm 3.0 \mathrm{~dB}$ re $\mu \mathrm{Pa} /$ $(\mathrm{m} / \mathrm{s})$. Observed pressures for the same vertical particle motion are about a factor of two greater than predicted by acoustic impedance. This is reasonable given that the noise may not necessarily be incident directly from above and may, in fact, be Scholte waves traveling horizontally along the seafloor (Rauch, 1980; Schreiner and Dorman, 1990). In

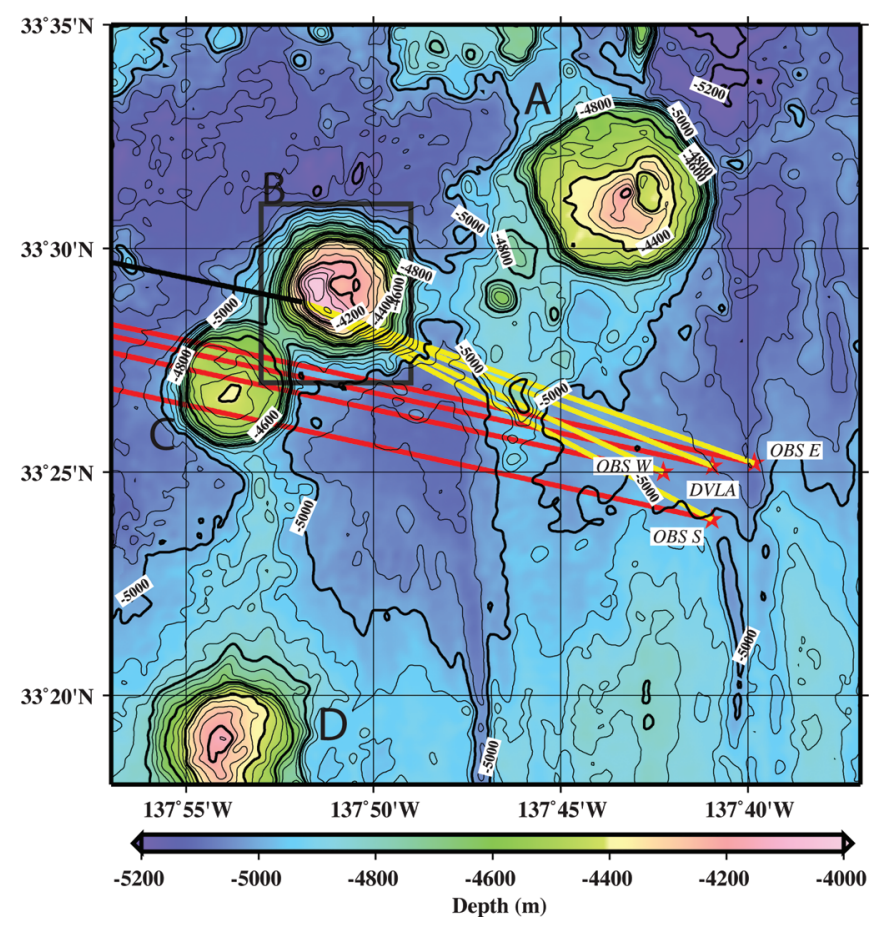

FIG. 5. The locations of the three OBSs and the DVLA with their geodesic paths (red lines) to the source locations are overlain on swath map bathymetry. This bathymetry is higher resolution but is available over a much smaller area than the satellite derived bathymetry in Fig. 1. The deep seafloor arrival pattern on the OBSs (Fig. 2) and the bottom-diffracted surfacereflected arrivals on DVLA-4250 (Fig. 3) are consistent with conversion from a PE predicted source-to-receiver path (black line) to a bottomdiffracted surface-reflected seamount-to-receiver path (yellow lines). 


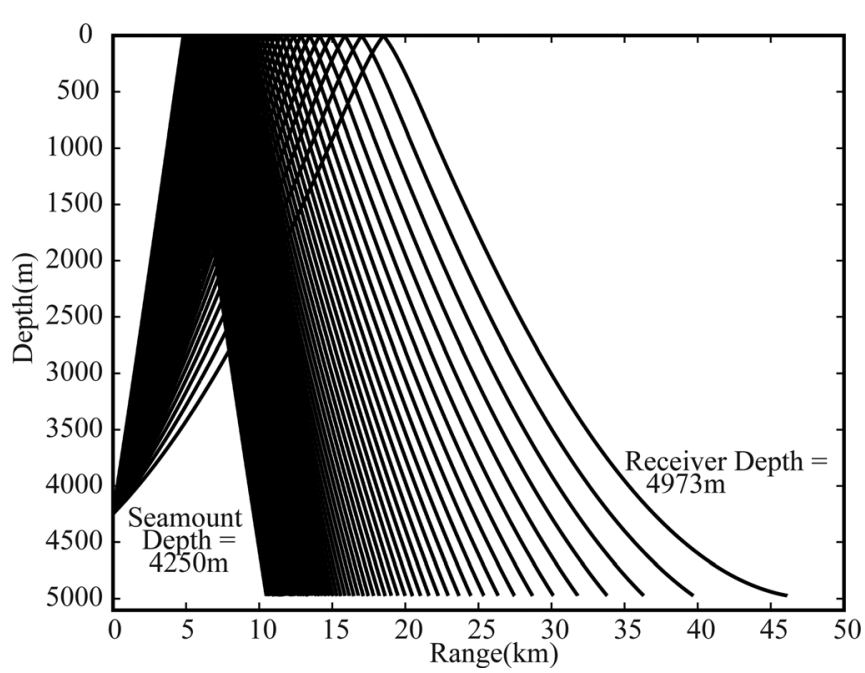

FIG. 6. Example of a ray tracing calculation for a bottom-diffracted surfacereflected path from an out-of-plane seamount at $4250 \mathrm{~m}$ depth and a line of receivers at the depth of the south OBS, $4973 \mathrm{~m}$. The calculation is based on a typical sound speed profile for LOAPEX (Fig. 7).

the signal and noise analysis in the following text, we convert pulse compressed vertical particle velocity traces and RMS levels (in meter/second) to pseudo-pressure (in micropascal) by adding $251.2 \mathrm{~dB}$.

Signal levels, noise levels, and SNRs for the seven major signals at $500 \mathrm{~km}$ range (Fig. 12) show why the highlighted deep seafloor arrivals become the largest arrivals on the ocean bottom. It is a combination of two factors. First, the ambient noise on the seafloor is more than $17 \mathrm{~dB}$ quieter than at $750 \mathrm{~m}$ above the seafloor. This is consistent with similar observations of ambient noise by Shooter et al. (1990). For example, Fig. 8 of Shooter et al. (1990) shows noise levels at $40 \mathrm{~Hz}$ decreasing about $18 \mathrm{~dB}$ from 4000 to $4800 \mathrm{~m}$ depth for local wind speeds less than $10 \mathrm{kn}$.

Second, the PE-predicted arrival from $500 \mathrm{~km}$ range is over $30 \mathrm{~dB}$ quieter at the seafloor than at $750 \mathrm{~m}$ above the seafloor. (On the east OBS the PE predicted arrival was undetectable at $500 \mathrm{~km}$ range.) So even though the bottom-

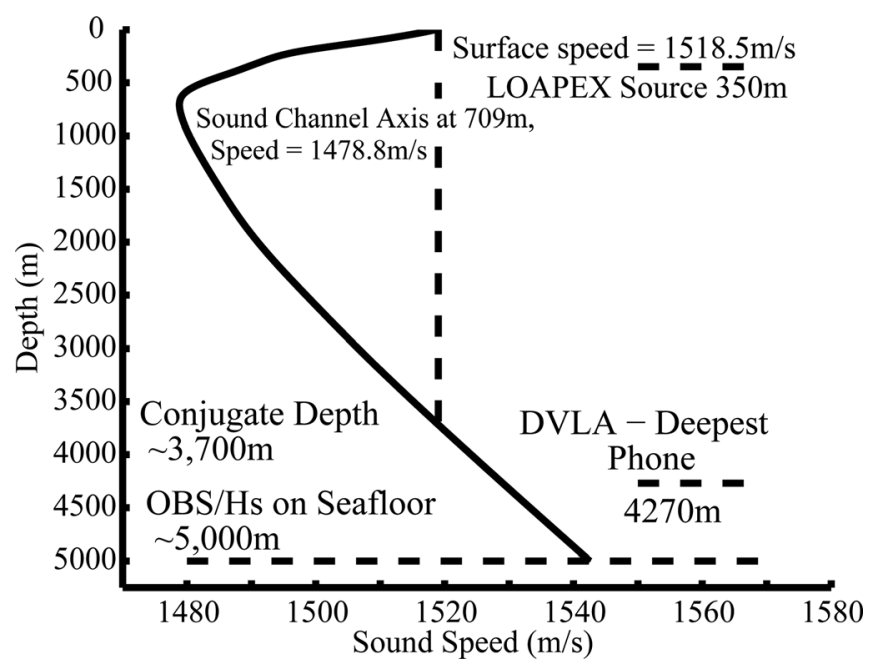

FIG. 7. A typical sound speed profile for the LOAPEX experiment showing the surface conjugate depth and depths of the sources and receivers used in this paper.

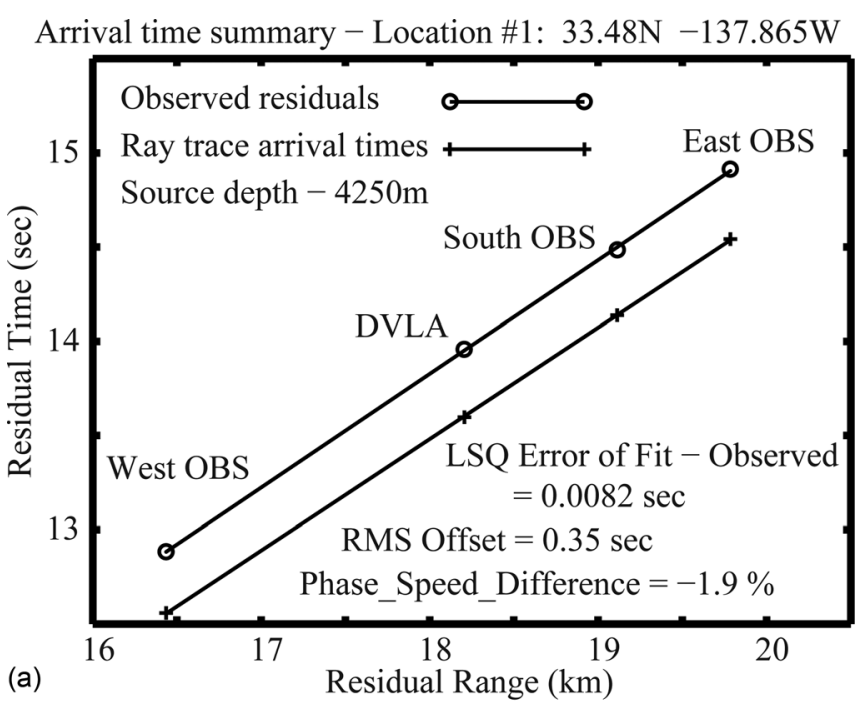

Arrival time summary - Location \#2: $33.48 \mathrm{~N}-137.8383 \mathrm{~W}$

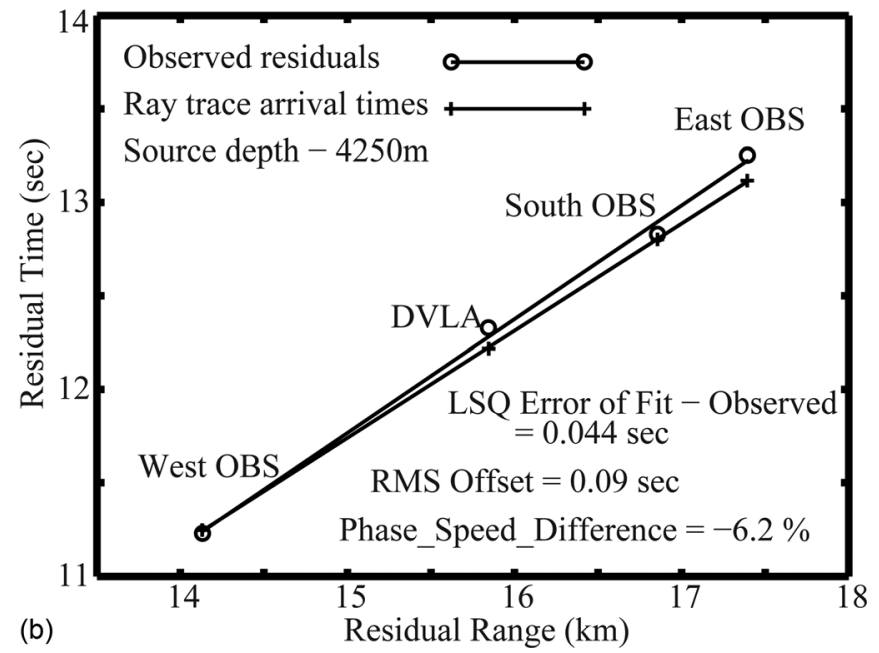

FIG. 8. Examples of residual arrival time data for two locations on Seamount B (Fig. 10). There are three measures of goodness of fit: The least square error of the linear regression, the RMS offset of the ray trace predicted arrival times from the observed arrival times, and the difference in phase speed (inverse slope) between observed and modeled data.

diffracted surface-reflected arrival on DVLA-4250 ("arrow" in Fig. 3) is barely perceptible above the ambient noise with an SNR of $3.6 \mathrm{~dB}$, on the seafloor this arrival has the largest SNR, 10-11 dB. As seen in Fig. 2, at longer ranges from 1000 to $2300 \mathrm{~km}$, the highlighted deep seafloor arrivals are as much as $20 \mathrm{~dB}$ louder than the PE-predicted arrivals.

\section{DISCUSSION}

Sixteen deep seafloor arrivals were observed on the south OBS, and we have shown that six of these (highlighted in yellow in Fig. 2, for ranges from 500 to $2300 \mathrm{~km}$ ) correspond to bottom-diffracted surface-reflected paths. This was possible because the pattern of six arrivals also appeared on the other two OBSs, and we could associate the arrival at $500 \mathrm{~km}$ range with clear water multiple energy on the DVLA. Paths for the remaining ten deep seafloor arrivals on the south OBS and other late arrivals on the other OBSs have not yet been identified. 

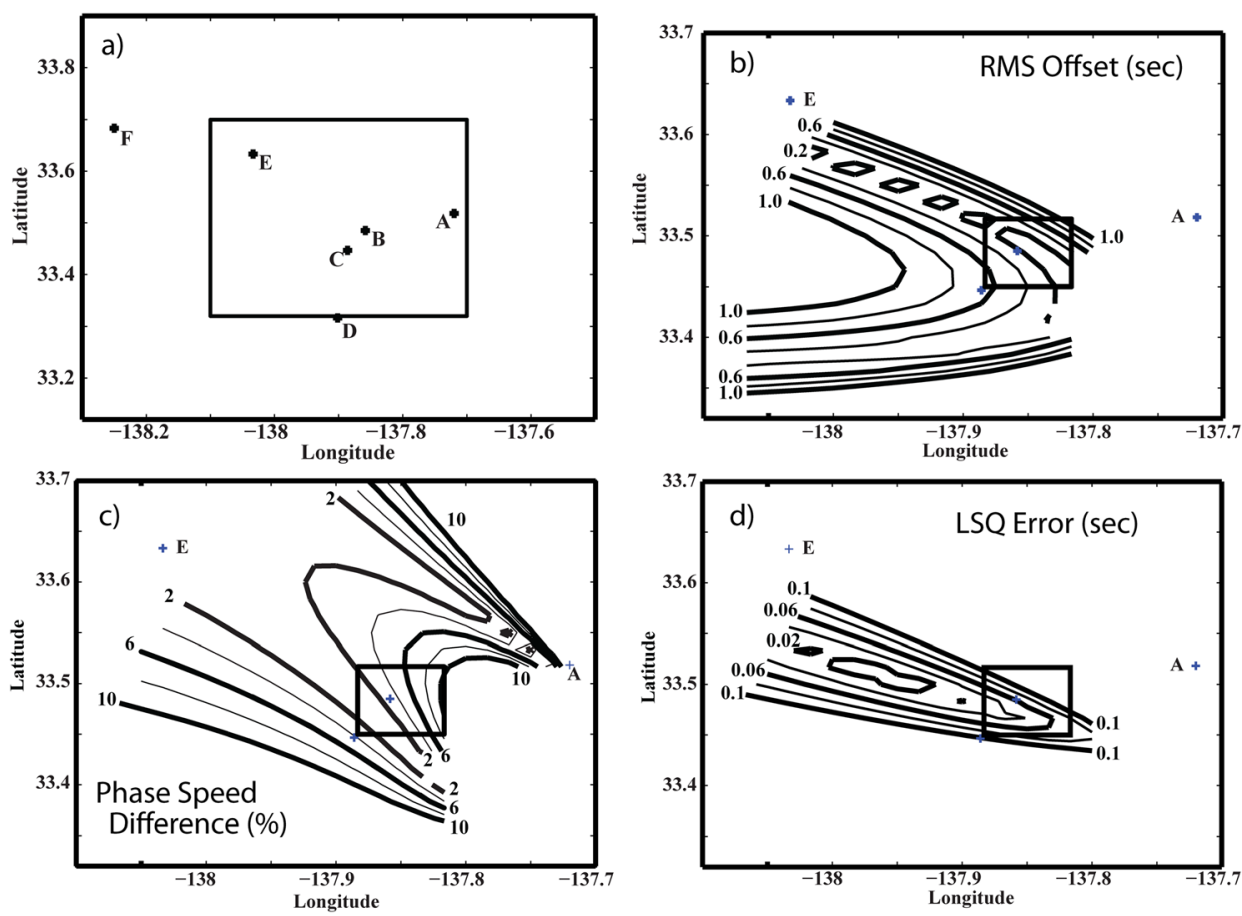

FIG. 9. (Color online) Error surfaces for a coarse grid (1 min spacing) over all six seamounts for transmissions from $500 \mathrm{~km}$ range. (a) Location of the six seamounts within the overall grid (Fig. 1), showing the area that is displayed in the other subplots. (b) Error surface of RMS offset in seconds. (c) Error surface of phase speed difference in percent. (d) Error surface of leastsquare error in seconds. The square box, around Seamount B, is the area used for the detailed grid $(0.1 \mathrm{~min}$ spacing) in Fig. 10.

Why should we care about deep seafloor arrivals and converted bottom-diffracted surface-reflected arrivals? After all, the converted bottom-diffracted surface-reflected arrival at DVLA-4250 is $30 \mathrm{~dB}$ weaker than the PE predicted arrival. But on the deep seafloor, the PE predicted energy is so weak and the ambient noise is so low that the deep seafloor arrivals appear as the strongest events, up to $20 \mathrm{~dB}$ louder than the principal ocean acoustic arrivals.

It would be tempting to dismiss DSF arrivals as simply bottom reverberation, "bottom junk," or coda that occur after principal acoustic arrivals. For example, shear wave resonances in the thin sediment layers on the seafloor can contribute

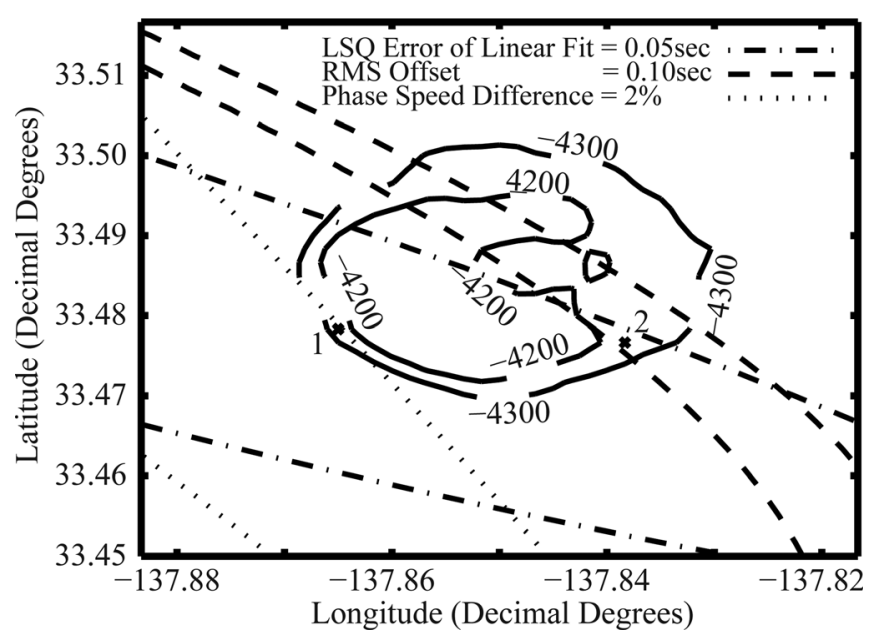

FIG. 10. Error contours are overlain on the 4200 and $4300 \mathrm{~m}$ isobaths at Seamount B. Three error contours are shown: Least-square fit of the linear regression to the observed residual arrival times, the RMS offset between the observed and ray traced arrival times at the four ranges, and the difference in the phase speed (slope of the linear fits) for the observed and ray traced arrivals. In each case the minimum values of each surface fall between the two contours shown. The travel time curves for test points 1 and 2 are given in Fig. 8. to coda on ocean bottom seismographs (Stephen et al., 2003). But coda amplitudes typically decrease from the principal arrival with occasional spikes that seem to appear randomly in the time series. At least some deep seafloor arrivals are robust, repeatable, and deterministic, and they have the largest amplitudes in the time series.

Dushaw et al. (1999) observed arrivals on deep seafloor receivers that they called "shadow zone arrivals," significant ray-like arrivals occurring $500-1000 \mathrm{~m}$ into the geometric shadow below cusps (caustics) in the predicted time front. Van Uffelen et al. (2009) explained the shadow zone arrivals in terms of penetration of acoustic energy below time front cusps due to internal-wave-induced scattering. In this paper, we present a mechanism, supported by observations, for energy to penetrate from the sound channel into the deep ocean at times not associated with cusps in the predicted time fronts. Our hypothesis predicts deterministic arrivals at times that may in some cases occur seconds after the finale of the time front. For example, the peaks in Fig. 6(a) of Dushaw et al. (Fig. 2 of Van Uffelen et al.) that occur after the predicted time front (between 57 and $59 \mathrm{~s}$ ) may be due to the same mechanism as the deep seafloor arrivals discussed here.

Dushaw et al. (1999) also mention problems caused by acoustic scattering from the seafloor near bottom-mounted sources and receivers: "Although the acoustic scattering from the ocean bottom is clearly an important effect for the receptions considered here, we do not feel that the topography near the arrays is known well enough for accurate predictions." This paper shows that a complete understanding of deep seafloor signals and ambient noise (at least in the $50-100 \mathrm{~Hz}$ band at the LOAPEX site) requires consideration of the detailed bathymetry around the receivers.

The depth dependence of deep-sea ambient noise in the $10-500 \mathrm{~Hz}$ band is a trade-off between noise from local winds and sea state, which should have a depth-independent 


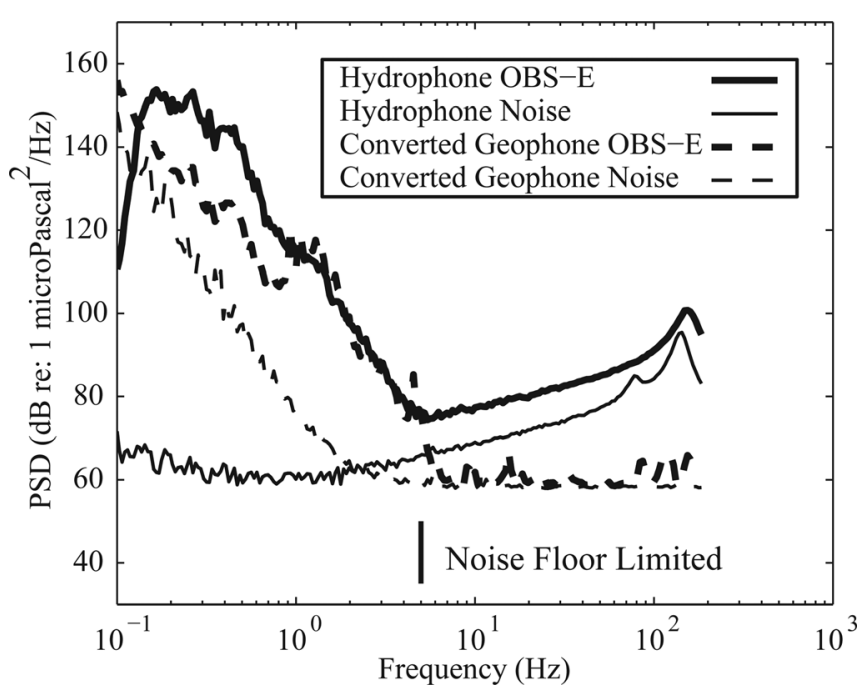

FIG. 11. Power spectral densities (PSD) for hydrophone and converted geophone (pseudo-pressure) channels are compared for seafloor noise and system noise intervals. One of the connectors on the north OBS shorted to seawater, so we use the hydrophone and geophone channels on the north OBS as proxies for system noise (labeled "hydrophone noise" and "converted geophone noise"). The vertical particle motion on the east OBS (OBS-E) has been converted to "pseudo-pressure" by multiplying by the acoustic impedance (see the text). Where the two hydrophone channels have similar slope, above about $5 \mathrm{~Hz}$, one can surmise that the ambient noise on the east OBS has fallen below the system noise. Similarly the geophone channel on the east OBS also falls to system noise above $5 \mathrm{~Hz}$. The south and west OBSs have similar spectra to the east OBS. The geophones and hydrophones on the OBSs were self-noise limited so that we can only place upper bounds on the true seafloor ambient noise and the SNRs are minimum values.

profile, and noise from distant shipping and wind-generated sources, which decreases substantially below the conjugate depth (Shooter et al., 1990). It appears that for this frequency band, ambient noise from distant wind and shipping is

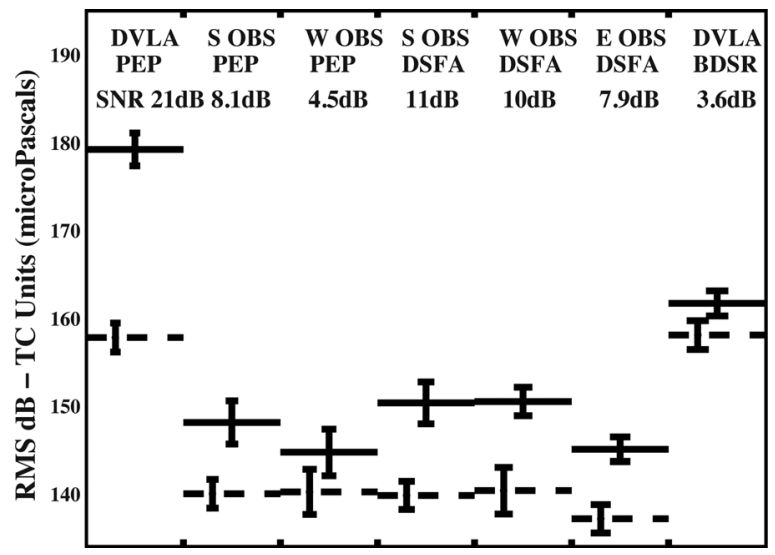

FIG. 12. Quantifying signal (horizontal solid lines) and noise (before the signal, horizontal dashed lines) for the seven major arrival-receiver combinations at $500 \mathrm{~km}$ range (T500). The three arrival types are: PE predicted (PEP), deep seafloor arrivals (DSFA), and bottom-diffracted surfacereflected (BDSR). The standard deviations of the 473 receptions that were cleanly received on all three OBSs (south, west, and east indicated by $\mathrm{S}$ OBS, W OBS, and E OBS, respectively) and DVLA-4250 (DVLA in this figure) are indicated by the vertical error bars. The signal-to-noise ratio, the difference between the solid and dashed lines, is given along the top for each arrival. All signal and noise levels are RMS values in the units of the time compressed pressure time series in micropascals. For the OBSs, vertical particle motion has been converted to "pseudo-pressure" as explained in the text. trapped in the sound channel above the conjugate depth (about 3,700 m, Fig. 7) (Gaul et al., 2007). Shooter et al. proposed bathymetric shielding (blockage by shallower bathymetry) and mode stripping as mechanisms for reducing the effect of distant sources on ambient noise on the deep seafloor. A comprehensive analysis of ambient noise on the LOAPEX experiment is beyond the scope of this paper; however, the bottom-diffracted surface-reflected mechanism proposed here is also dependent on bathymetry, but rather than blocking the sound, it enhances the sound by providing a means for noise from distant sources to penetrate to deep receivers.

Prior to the SNR analysis (Fig. 12) and the observation of bottom-diffracted surface-reflected arrivals on DVLA4250 (Fig. 3), we had assumed that the noise floors on the OBSs at $5000 \mathrm{~m}$ depth and the DVLA-4250 were similar and that deep seafloor arrivals were not observed on the DVLA at $4250 \mathrm{~m}$ and shallower. This implied that the deep seafloor arrivals were strong at the seafloor and attenuated with height above the seafloor; this led us to believe that Scholte (seafloor interface) waves were a probable mechanism for deep seafloor arrivals (Stephen et al., 2009). Although we have shown that the interface wave mechanism is not applicable in this case (for six of the 16 late arrivals on the south OBS), excitation of seafloor interface waves by secondary scattering from bottom features has been reported previously (Dougherty and Stephen, 1987; Schreiner and Dorman, 1990) and has been observed in numerical simulations of bottom interaction (Dougherty and Stephen, 1988; Stephen and Swift, 1994).

The deep seafloor arrival mechanism has implications beyond long-range ocean acoustics. The LOAPEX experimental geometry is in many respects the reciprocal of the earthquake T-phase geometry. In the former, the sources are in the sound channel, and the OBS receivers are on the seafloor. In the latter, an earthquake excites vibrations on the seafloor and the receivers are hydrophones near the sound channel (Dziak, 2001; Dziak et al., 2004; Okal, 2008). Coherent arrivals from out-of-plane seamounts and bathymetry have also been observed for earthquake T-phases in the $10-90 \mathrm{~Hz}$ band (Chapman and Marrett, 2006; Graeber and Piserchia, 2004). In the reciprocal to the bottom-diffracted surface-reflected mechanism proposed here, earthquakes below the deep seafloor can excite long-range acoustic Tphases by radiating from shallower bathymetric features (Williams et al., 2006).

In the triangulation analysis in the preceding text, we assumed that the PE predicted arrival pattern at DVLA-4250 was a proxy for the PE predicted arrival pattern at all of the test points around Seamount B. The similarity of the deep seafloor arrival characteristics on the OBSs with the PE predicted arrival characteristics on DVLA-4250 for the $500-2300 \mathrm{~km}$ range supports this assumption (Fig. 4). It is especially clear at $500 \mathrm{~km}$. This assumption is not valid, however, for the source at $250 \mathrm{~km}$ range from the DVLA. For this source, PE modeling indicates that the sound skips over the seamount near $230 \mathrm{~km}$ range and no bottomdiffracted surface-reflected paths are observed, even though strong arrivals are observed at the bottom of the DVLA at 
$250 \mathrm{~km}$ range (see the left most traces in the panels in Fig. 2).

Now in the triangulation analysis we also needed an arrival time for the $\mathrm{PE}$ predicted path from the transmission station to test points around the seamounts and receivers (black line in Fig. 5). We assumed that the PE predicted group speed (range divided by PE predicted arrival time) was constant across the area under study, used the group speed of the PE predicted arrival at DVLA-4250 regardless of the actual depth at the test point, and computed the arrival time for the range of the test point. We feel this is valid because the PE predicted group speed varies very little for ranges from 500 to $2300 \mathrm{~km}$ (so why would $20 \mathrm{~km}$ more or less make much difference) and varies very little with depth (from the DVLA at $4250 \mathrm{~m}$ to the south and west OBSs around $5000 \mathrm{~m}$ depth). At $500 \mathrm{~km}$ range, the error introduced into the travel times from this approximation was about $0.02 \mathrm{~s}$. Combining this with a clock synchronization accuracy of $0.02 \mathrm{~s}$ and a first-break arrival time picking error of $0.02 \mathrm{~s}$ for $500 \mathrm{~km}$ range [Fig. 4(a)], gives a combined estimated error of $0.06 \mathrm{~s}$, well within the $0.1 \mathrm{~s}$ contour level for the RMS offset in Fig. 10. Nonetheless, an alternative, more rigorous, approach would be to obtain the arrival time from PE model predictions for the location and depth of the test point.

Even though the three error criteria in Fig. 10 are not independent, all of them point to Seamount B, an out-of-plane diffractor. The RMS offset at test points 1 and 2 on Seamount B are 0.35 and $0.09 \mathrm{~s}$, respectively. Could the deep seafloor arrivals be in-plane bottom-diffracted surfacereflected from Seamount C? The RMS offset for points on Seamount $\mathrm{C}$ is $0.6 \mathrm{~s}$ [the plus mark at the lower left corner of the box in Fig. 9(a)]. We are confident that our errors are sufficiently small to distinguish between Seamounts C and B.

\section{CONCLUSIONS}

Deep seafloor arrivals are the largest amplitude arrivals on the deep seafloor $(\sim 5000 \mathrm{~m})$ at ranges near to and greater than $500 \mathrm{~km}$ during LOAPEX. They are bigger than the PE predicted and deep shadow zone arrivals, the tails beneath ray caustics due to internal-wave-induced scattering (Van Uffelen et al., 2009). Deep seafloor arrivals are extremely robust. They survive pulse compression. They survive stacking, in some cases of over 600 traces. The appearance of the six deep seafloor arrivals on all three OBSs, and their similarity to the PE predicted arrivals on DVLA-4250, is also remarkably consistent.

The deep seafloor arrivals in Figs. 2 and 4 are very distinct. There is little, if any, indication of coda (tails after the principal arrival) or reverberation that is often seen on seafloor reflections for example. The scattering point appears to be discrete. Given the rough and heterogeneous nature of the sub-seafloor (on the scale of an acoustic wavelength of about $20 \mathrm{~m}$ ), it is surprising that there are not more scattering points within the area of a given seamount.

It is quite clear that at least a subset of deep seafloor arrivals on the OBSs (for example, six events of 16 deep seafloor arrivals on the south OBS) are the same event as the bottom-diffracted surface-reflected arrival on DVLA-4250. Both are bottom-diffracted surface-reflected paths converted from PE predicted paths at the out-of-plane Seamount B. This mechanism provides a means for acoustic signals and noise from distant sources to appear with significant strength on the deep seafloor.

\section{ACKNOWLEDGMENTS}

The idea to deploy OBSs on the 2004 LOAPEX experiment was conceived at a workshop held at Woods Hole in March 2004 (Odom and Stephen, 2004). The OBS/Hs used in the LOAPEX field program were provided by Scripps Institution of Oceanography under the U.S. National Ocean Bottom Seismic Instrumentation Pool (SIO-OBSIP, http:// www.obsip.org). The OBS/H deployments themselves were co-funded through direct funding to SIO-OBSIP by the National Science Foundation and by Woods Hole Oceanographic Institution under a grant from the WHOI Deep Ocean Exploration Institute. The OBS/H data are archived at the Incorporated Research Institutions for Seismology (IRIS) Data Management Center. Figures 1 and 5 were prepared using the Generic Mapping Tool (http:// gmt.soest.hawaii.edu/) (Wessel and Smith, 1998). The LOAPEX source deployments and the moored DVLA receiver deployments were funded by the Office of Naval Research under Award Nos. N00014-03-1-0181 and N00014-03-1-0182. The data reduction and analysis in this paper were funded by the Office of Naval Research under Award Nos. N00014-06-1-0222 and N00014-10-1-0510. Additional post-cruise analysis support was provided to RAS through the Edward W. and Betty J. Scripps Chair for Excellence in Oceanography. We greatly appreciate the many useful and insightful comments of two anonymous reviewers.

Baggeroer, A. B., and Kuperman, W. A. (1983). "Matched field processing in ocean acoustics," in Acoustic Signal Processing for Ocean Exploration, edited by J. M. F. Moura and I. M. G. Lourtie (Kluwer, Dordrecht), pp. 79-114.

Birdsall, T. G. (1976). "On understanding the matched filter in the frequency domain,” IEEE Trans. Educ. 19, 168-169.

Birdsall, T. G., and Metzger, K. (1986). "Factor inverse matched filtering," J. Acoust. Soc. Am. 79, 91-99.

Birdsall, T. G., Metzger, K., and Dzieciuch, M. A. (1994). "Signals, signal processing, and general results," J. Acoust. Soc. Am. 96, 2343-2352.

Chapman, N. R., and Marrett, R. (2006). "The directionality of acoustic T-phase signals from small magnitude submarine earthquakes," J. Acoust. Soc. Am. 119, 3669-3675.

Clay, C. S., and Medwin, H. (1977). Acoustical Oceanography: Principles and Applications, edited by M. E. McCormick (Wiley-Interscience, New York), $544 \mathrm{pp}$.

Dougherty, M. E., and Stephen, R. A. (1987). "Seismic scattering from seafloor features in the ROSE area," J. Acoust. Soc. Am. 82, 238-256.

Dougherty, M. E., and Stephen, R. A. (1988). "Seismic energy partitioning and scattering in laterally heterogeneous ocean crust," Pure Appl. Geophys. 128, 195-229.

Dushaw, B. D., Howe, B. M., Mercer, J. A., and Spindel, R. (1999). "Multimegameter-range acoustic data obtained by bottom-mounted hydrophone arrays for measurement of ocean temperature," IEEE J. Ocean. Eng. 24, 202-214.

Dziak, R. P. (2001). "Empirical relationship of T-wave energy and fault parameters of northeast Pacific Ocean earthquakes," Geophys. Res. Lett. 28, doi: 10.1029/2001GL012939, 2537-2570. 
Dziak, R. P., Bohnenstiehl, D. R., Matsumoto, H., Fox, C. G., Smith, D. K., Tolstoy, M., Lau, T.-K., Haxel, J., and Fowler, M. J. (2004). "P-and Twave detection thresholds, Pn velocity estimate, and detection of lower mantle and core P-waves on ocean sound-channel hydrophones at the Mid-Atlantic Ridge," Bull. Seismol. Soc. Am. 94, 665-677.

Ewing, M., and Worzel, J. L. (1948). "Long-range sound transmission," Propagation of Sound in the Ocean, Memoir (Geological Society of America, New York), pp. 1-32.

Gaul, R. D., Knobles, D. P., Shooter, J. A., and Wittenborn, A. F. (2007). "Ambient noise analysis of deep ocean measurements in the Northeast Pacific,” IEEE J. Ocean. Eng. 32, 497-512.

Golomb, S. W. (1982). Shift Register Sequences (Aegean Park Press, Laguna Hills, CA), 247 pp.

Graeber, F. M., and Piserchia, P.-F. (2004). "Zones of T-wave excitation in the NE Indian Ocean mapped using variations in backazimuth over time obtained from multi-channel correlation of IMS hydrophone triplet data," Geophys. J. Int. 158, 239-256.

Jensen, F. B., Kuperman, W. A., Porter, M. B., and Schmidt, H. (1994). Computational Ocean Acoustics (American Institute of Physics, New York), 612 pp.

Mercer, J., Andrew, R., Howe, B. M., and Colosi, J. (2005), Cruise Report: Long-range Ocean Acoustic Propagation EXperiment (LOAPEX), (Applied Physics Laboratory, University of Washington, Seattle, WA), 116 pp.

Mercer, J. A., Colosi, J. A., Howe, B. M., Dzieciuch, M. A., Stephen, R., and Worcester, P. F. (2009). "LOAPEX: The long-range ocean acoustic propagation experiment," IEEE J. Ocean. Eng. 34, 1-11.

Metzger, K. M., Jr. (1983). "Signal processing equipment and technique for use in measuring ocean acoustic multipath structures," Ph.D. thesis, University of Michigan, Ann Arbor.

Munk, W., Worcester, P., and Wunsch, C. (1995). Ocean Acoustic Tomography (Cambridge University Press, Cambridge, U.K.), 433 pp.

Odom, R. I., and Stephen, R. A. (2004). Proceedings of the Seismo-Acoustic Applications in Marine Geology and Geophysics Workshop, Woods Hole Oceanographic Institution, March 24-26, 2004 (Applied Physics Laboratory, University of Washington, Seattle, WA), 55 pp.

Okal, E. (2008). "The generation of T waves by earthquakes," Adv. Geophys. 49, 2-65.

Rauch, D. (1980). Seismic Interface Waves in Coastal Waters: A Review (SACLANT ASW Research Center, San Bartolomeo, Italy), 103 pp.
Schreiner, M. A., and Dorman, L. M. (1990). "Coherence lengths of seafloor noise: Effect of ocean bottom structure," J. Acoust. Soc. Am. 88, 1503-1514.

Shooter, J. A., DeMary, T. E., and Wittenborn, A. F. (1990). "Depth dependence of noise resulting from ship traffic and wind," IEEE J. Ocean. Eng. 15, 292-298.

Smith, W. H. F., and Sandwell, D. T. (1997). "Global seafloor topography from satellite altimetry and ship depth soundings," Science 277, 1956-1962.

Stephen, R. A., Bolmer, S. T., Dzieciuch, M. A., Worcester, P. F., Andrew, R. K., Buck, L. J., Mercer, J. A., Colosi, J. A., and Howe, B. M. (2009). "Deep seafloor arrivals: An unexplained set of arrivals in long-range ocean acoustic propagation," J. Acoust. Soc. Am. 126, 599-606.

Stephen, R. A., Bolmer, S. T., Udovydchenkov, I. A., Dzieciuch, M. A., Worcester, P. F., Andrew, R. K., Mercer, J. A., Colosi, J. A., and Howe, B. M. (2012). "Analysis of deep seafloor arrivals observed on NPAL04," WHOI Technical Report WHOI-2012-09 (Woods Hole Oceanographic Institution, Woods Hole, MA), 88 pp.

Stephen, R. A., Bolmer, S. T., Udovydchenkov, I., Worcester, P. F., Dzieciuch, M. A., Van Uffelen, L., Mercer, J. A., Andrew, R. K., Buck, L. J., Colosi, J. A., and Howe, B. M. (2008). NPAL04 OBS data analysis. Part 1: Kinematics of deep seafloor arrivals, WHOI Technical Report 2008-03 (Woods Hole Oceanographic Institution, Woods Hole, MA), 95 pp

Stephen, R. A., Spiess, F. N., Collins, J. A., Hildebrand, J. A., Orcutt, J. A., Peal, K. R., Vernon, F. L., and Wooding, F. B. (2003). "Ocean seismic network pilot experiment," Geochem., Geophys., Geosyst. 4, doi: 10.1029/2002GC000485, 1-38.

Stephen, R. A., and Swift, S. A. (1994). "Modeling seafloor geoacoustic interaction with a numerical scattering chamber," J. Acoust. Soc. Am. 96, 973-990.

Van Uffelen, L. J., Worcester, P. F., Dzieciuch, M. A., and Rudnick, D. L. (2009). "The vertical structure of shadow-zone arrivals at long range in the ocean," J. Acoust. Soc. Am. 125, 3569-3588.

Wessel, P., and Smith, W. H. F. (1998). "New, improved version of generic mapping tools released," EOS Trans. Am. Geophys. Union 79, 579.

Williams, C. M., Stephen, R. A., and Smith, D. K. (2006). "Hydroacoustic events located at the intersection of the Atlantis and Kane Transform Faults with the Mid-Atlantic Ridge," Geochem., Geophys., Geosyst. 7, doi:10.1029/2005GC001127, 1-28. 